\title{
Molecular Diversity and Population Structure in Breeding Lines of Castor (Ricinus communis L.)
}

\author{
Usha Kiran Betha* and C. Lavanya
}

ICAR-Indian Institute of Oilseeds Research (IIOR), Rajendranagar, Hyderabad-530030, India

*Corresponding author

\author{
A B S T R A C T
}

\begin{tabular}{|l|}
\hline Ke y w o r d s \\
Castor, EST-SSR, \\
Genetic diversity, \\
Germplasm, \\
Molecular marker \\
\hline Article Info \\
\hline $\begin{array}{l}\text { Accepted: } \\
\text { 15 January } 2019 \\
\text { Available Online: } \\
\text { 10 February } 2019\end{array}$ \\
\hline
\end{tabular}

\section{Introduction}

Castor (Ricinus communis L.) with $2 \mathrm{n}=2 \times=20$ of Euphorbiaceae is one of the ancient and important non-edible oil seed crops cultivated in many tropical and subtropical regions. It is a native crop of tropical Africa, mainly grown for castor oil and cake (Weiss, 2000). Castor is a monotypic genus and the classification of subspecies is based on geographical diversity (Moshkin, 1986). The castor oil is primarily used in industry as a lubricant for all types of heavy machinery, locomotive bearings, steam
Castor is a non-edible oilseed crop, primarily grown for oil containing an unusual hydroxy fatty acid and ricinoleic acid (80-90\%) of the total fatty acids. Commercial exploitation of heterosis in castor was successful in India due to the development of stable pistillate lines from a dominant and epistatic "S" type pistillate source. Diversification of pistillate sources using NES and other new sources necessitated the need for identification of diverse male combiners among the existing pool of male combiners. In this study, 60 breeding lines/genotypes were characterized for genetic diversity and population structure using EST-SSRs primers. SSR allelic variation was low as indicated by the average mber of alleles (2.8), gene diversity (0.53) and polymorphic information content $(0.45)$. (membership coefficients $(\geq 0.75)$ ) and $66.7 \%$ gens were classified into 3 populations $(\mathrm{K}=3)$ and the remaining $33.3 \%$ genotypes into admixture group in STRUCTURE analysis. The genetic diversity information exploit heterosis for development of hybrids. 
and productivity among the major castor producing countries like Mozambique, China mainland, Ethopia and Brazil. Together, these countries, account for $88.6 \%$ (16.44 lakh tons) of the castor seeds produced globally (FAOSTAT, 2013). India with varied ecosystems is one of the centers of castor diversity (Anjani, 2012). There is a lot of scope to increase the productivity by harnessing heterosis existing in the crop to develop improved cultivars and hybrids in castor. In castor, genetic improvement for yield and yield contributing traits was achieved through mutation breeding, recurrent selection, pedigree selection, hybridization (involving single, double, triple crosses), and selection for different traits (Lavanya et al., 2003a, 2003b; Lavanya et al., 2008, Severino et al., 2012). Knowledge on the extent of genetic diversity is critical to assess the variability in the trait of importance, to choose the parents and to estimate the success of a breeding program. The hybrid vigor in castor depends mainly on the genetic diversity and individual combining ability of the parents (Ramana et al., 2003; Lavanya et al., 2006). The prior information on genetic diversity and relatedness is essential for heterosis breeding and hybrid development in any crop. Previously, genetic diversity in castor was studied using agro-morphological and biochemical markers (Athma et al., 1982; Sathaiah and Reddy, 1984; Figueredo et al., 2004; Costa et al., 2006; Milani et al., 2009). Majority of the agronomic characters and sex expression in castor are highly sensitive to environmental conditions like seasons, temperature, day length etc. (Lavanya, 2002; Lavanya and Gopinath, 2008; Lavanya and Solanki, 2010). Absence of sufficient diversity in castor (for isozymes), limited the number of morphological and biochemical markers (Soltis et al., 1992), and environmental factors limited their use in diversity studies. The precise cataloguing of germplasm resources, including genotypes and cultivars by molecular DNA markers has gained a lot of attention in recent times (Wang et al., 2007; Allan et al., 2008; Foster et al., 2010; Kanti et al., 2014; 2015; Senthilvel et al., 2016). Assessment of genetic diversity with DNA markers differentiates the different accessions quickly using only a small quantity of DNA without any environmental influence. In the present study, we examined the genetic diversity of 60 castor genotypes, including 8 pistillate lines and 52 male / varietal / breeding lines that are predominantly used in the breeding programme. EST-SSRs were used to assess the relative diversity between these genotypes to identify diverse lines for crossing programme in castor.

\section{Materials and Methods}

\section{Genomic DNA extraction and SSR analysis}

A set of 60 commonly used, constitutionally different breeding lines of castor developed at the Indian Institute of Oilseeds Research (IIOR) and other castor ACRIP centre's were used in the present study. The pedigree and major morphological characters of the genotypes were given in Table 1 . In this study, a representative plant of each genotype was selected and the total genomic DNA was extracted from fresh leaf samples as described by Doyle and Doyle (1990) with slight modifications. The quality and quantity were measured through $0.8 \%$ agarose gel electrophoresis. EST-SSR markers were developed in the IIOR from the publicly available ESTs $(64,756)$; a set of 35 primer pairs designed was used for genotyping. The PCR reactions were performed in $10 \mu \mathrm{l}$ reaction volume containing $1 \times$ PCR buffer with $1.5 \mathrm{mM} \mathrm{MgCl}_{2}$ (Genei, India), $0.08 \mathrm{mM}$ each of dNTPs (Genei, India), 5 pm of each forward and reverse primer, 0.2 U Taq DNA polymerase (Genei, India) and $25 \mathrm{ng}$ template DNA. DNA amplification was performed in 
the Master cycler Gradient Eppendorf version 2.1 (Eppendorf, USA). DNA was predenatured at $94{ }^{\circ} \mathrm{C}$ for $5 \mathrm{~min}$ followed by 30 cycles of denaturation at $92{ }^{\circ} \mathrm{C}$ for $30 \mathrm{sec}$, primer annealing at $56{ }^{\circ} \mathrm{C}$ for $30 \mathrm{sec}$ and primer extension at $72{ }^{\circ} \mathrm{C}$ for $30 \mathrm{sec}$ followed by a final extension at $72{ }^{\circ} \mathrm{C}$ for $7 \mathrm{~min}$. The PCR product was separated in $6 \%$ polyacrylamide gels on a Sequi-Gen (BioRad, USA) sequencing unit for $3 \mathrm{~h}$ in $1 \times \mathrm{TBE}$ at $100 \mathrm{~W}, 50 \mathrm{~mA}$. After electrophoresis, the bands were visualized by silver-staining as reported by Tegelstrom (1992) with slight modifications

\section{Genetic analysis}

The genetic diversity estimates viz., number of alleles, gene diversity (expected heterozygosity; $\mathrm{He}$ ) and polymorphic information content (PIC) were obtained using Power Marker version 3.25 (Liu and Muse, 2005). The SSR allelic data were used to construct neighbor-joining (NJ) based on pair-wise simple matching coefficients using DARwin version.5.0.158 (Perrier and Jacquemoud-Collet, 2006) to understand the genetic relationships among genotypes. Principal coordinates analysis (PCoA) was also performed to visualise the overall representation of diversity in the genotypes.

\section{Structure analysis}

The genetic structure of the accessions was also investigated using a model-based clustering algorithm (STRUCTURE v.2.3.4) that genetically separates groups according to allele frequencies (Pritchard et al., 2000). The possible number of $\mathrm{K}$ was assumed from 1 to 10 in order to determine the optimal K. Each run consisted of a burn-in period of 100,000 steps followed by 200,000 Monte Carlo Markov chain replicates, assuming an admixture model and correlated allele frequencies. The mean posterior probability
(LnP(D)) values per $\mathrm{K}$ were obtained based on 10 replications. The delta $\mathrm{K}$ measure (Evanno et al., 2005) was used to determine the $\mathrm{K}$ as implemented in the online version of STRUCTURE HARVESTER (http://tayloro. biologyucla.edu/Struct_harvest) (Earl and VonHoldt, 2012).

\section{Results and Discussion}

\section{Genetic diversity}

Genetic diversity in the genotypes is the foundation for any breeding program for crop improvement. In the present study, a set of 60 breeding lines used generally in breeding program was characterized for the extent of genetic diversity, genetic relatedness and population structure using 35 EST-SSR markers developed in IIOR. Microsatellites markers are considered ideal for characterizing genetic diversity and relatedness among the genotypes due to codominant nature and high reliability. SSR markers are mostly used in castor for genetic diversity studies (Allan et al., 2008; Bajay et al., 2009; Qiu et al., 2010; Kanti et al., 2014, 2015; Senthilvel et al., 2016). Even though, SNPs are widely used to study genetic diversity in crops now-a-days, SSRs are preferred due to their multi-allelic nature, which provides more information per locus (Remington et al., 2001). For this study 35 EST- SSR markers were selected randomly from the designed EST-SSR primer pairs based on the amplification, amplicon size and polymorphism to characterize 60 breeding lines out of which, five were monomorphic. A total of 85 alleles were observed with 30 polymorphic SSR markers. The number of alleles per locus ranged from 2 to 4 with a mean of 2.8 (Table 2). The major allele frequency ranged from 0.38 to 0.68 with an average of 0.54 . SSR allelic diversity in the genotypes studied were low $(\mathrm{NA}=2.8$, $\mathrm{PIC}=0.45$ ), which could be because of using 
EST-SSR markers. In general, EST-SSR markers were observed to be less polymorphic, but as functional markers the polymorphism is associated with the coding regions and detects the true genetic diversity available inside or adjacent to the genes (Eujayl et al., 2002; Maestri et al., 2002; Thiel et al., 2003). Low SSR polymorphism in castor is also evident from previous studies. Qiu et al., (2010) reported that the EST-SSR alleles ranged from 2 to 6 with an average of 2.97 alleles per locus among 24 genotypes. Similarly, Bajay et al., (2009) reported an average of 3.3 alleles per locus using 38 germplasm accessions. Allan et al., (2008) reported an average of 3.1 alleles per locus among 200 genotypes. Senthilvel et al., (2016) reported an average of 2.97 alleles in a collection of inbred lines (144) from the core collection of castor. Gene diversity $(\mathrm{He})$ per locus ranging from 0.44 to 0.63 with an average of 0.53 was observed in this study. These values are, slightly higher than the moderate levels of gene diversity per locus (0.38 - 0.42) reported by Bajay et al., (2014); Kanti et al., (2014) and Senthilvel et al., (2016). Allan et al., (2008), on the other hand reported very low level of gene diversity $(0.188)$ in worldwide genotyping of castor germplasm accessions. The relatively low levels of He revealed by molecular markers in castor can be due to breeding bottlenecks, where only a small proportion of the variability of the gene pools was funneled through. The PIC value ranged from 0.35 to 0.62 with an average of 0.45 (Table 2). Kanti et al., (2014) reported PIC value ranging from 0.12 to 0.35 with an average of 0.37 , comparable to the observed PIC value in this study, in castor germplasm collected from Andaman and Nicobar Islands, India. However, large range of PIC values (0.07 0.73 ; $0.01-0.62$ ) but with a low mean value of 0.32 and 0.36 was observed by Qiu et al., (2010) and Senthilvel et al., (2016) respectively. The PIC value is indicative of the effectiveness and usefulness of SSR loci and measures the information about a given marker locus for the pool of genotypes (Kupper et al., 2011). The level of polymorphism is influenced by the number of genotypes, type of plant material used in the study. For instance, Allan et al., (2008) studied genetic diversity of 200 genotypes using gSSR markers and observed an average PIC value of 0.4. Whereas, Senthilvel et al., (2016) studied 144 diverse inbred lines derived from core collection of castor germplasm and found slightly lower mean PIC value (0.36). In our study, nine markers showed > 0.5 PIC value (mRcDOR49, mRCDOR55, mRcDOR69, mRcDOR76, mRcDOR106, mRcDOR153, mRCDOR177, mRcDOR203 and mRcDOR240) indicating their usefulness for applications in diversity analysis. In this study low genetic diversity at the molecular level is observed, which confirmed the previous findings. Nevertheless, low SSR polymorphism in castor is a concern that would limit their use for mapping important traits. Many studies on assessment of genetic diversity in castor germplasm showed low levels of variability regardless of the marker systems employed (Allan et al., 2008; Gajeria et al., 2010; Foster et al., 2010; Qiu et al., 2010; Bajay et al., 2010; Rivarola et al., 2011; Pecina-Quintero et al., 2013; Wang et al., 2013; Vivodik et al., 2014; Kanti et al., 2014, 2015; Senthilvel et al., 2016). The extensive agro-morphological diversity for vegetative, reproductive and seed traits observed in the castor genotypes has not reflected at molecular level genetic variability. However, use of few markers, different marker systems and plant material for evaluation of genetic variation might be the reason for detecting contradictory levels of diversity in castor. The low genetic variation in castor could probably be due to selected cultivation, domestication and long term propagation of few varieties (Sujatha $e t$ al., 2008). 


\section{Genetic relationship}

Cluster analysis showed three major clusters (I, II, III) and sub-groups within the major clusters (Ia, Ib, IIa, IIb, IIIa, IIb, IIIc). Cluster I included 20 genotypes, Cluster II included 21 and Cluster III consisted of 19 genotypes. A neighbor- joining (NJ) tree depicting genetic relationships between 60 castor genotypes based on pair-wise dissimilarity coefficients is shown in Figure 1. Overall, pair-wise simple matching coefficients ranged from 0.00 (DPC 14 and DPC 16) to 0.88 (DCS 25 and DCS 102; 48-1 and DPC 9) with an average of 0.48 .

The pairwise simple matching coefficients of Cluster I ranged from 0.2 (JI 336 and DCS 1)) to 0.75 (DCS 45 and DCS 92), cluster II ranged from 0.13 (DCS79 and DCS 80) to 0.84 (DCS 60 and DPC 17) and cluster III ranged from 0.00 (DPC 14 and DPC 16) to 0.8 (JI 220 and DCS 38; DCS 16 and DCS 81). Cluster Ia consists of four male lines: DCS 1, DCS 2, DCS 3and DCS 5 which were derivatives involving Bhagya variety as the common parent. Cluster IIb consists of 8 male lines and one non- revertant pistillate line DPC 9 with distinct morphological characters like green stem colour, single bloom, spiny capsules, early duration (110-120 days), resistant to Fusarium wilt used in the development of two hybrids like DCH 177 and YRCH1. DCS 92, DCS 94 are derivatives from NES type of line NES19. DPC-9 and DCS 103 has VP-1 background. Cluster IIa is the major sub cluster consisting of 15 genotypes. It consists of one pistillate line JP81 was also closely related to male lines derived by involving an $\mathrm{S}$ type of pistillate lines like LRES 17, M 584. This cluster contains two best male lines 48-1 and DCS 9 which are the parental lines of the popular hybrids GCH 4 and DCH 177 respectively. $48-1$ is a male line with a red stem, non-spiny capsules, zero bloom, Fusarium wilt resistant, moderately resistant to Botryotinia grey mold is largely grown as a variety. DCS 86 and DCS 86-1 are the cross derived male lines with non-spiny capsule from 48-1. Cluster IIb includes one new pistillate line, DPC 17, a cross derivative of M-619 XJI 225 with red stem colour, double bloom, spiny capsules is revertant type of pistillate line. Cluster IIIa includes three male lines (DCS 102, DCS 100, DCS 49) and five pistillate lines. Among the 5 pistillate lines DPC 13 and DPC 14 were derivatives of VP-1 based ' $\mathrm{S}$ ' type of pistillate source while DPC 15 and DPC 16 were developed using 'NES' source of pistillate line (Lavanya, 2002; Lavanya and Gopinath, 2008) and DPC 11 was developed from a different source of pistillate expression (1631-11 X 1501-4). Cluster IIIb includes five genotypes (DCS 68, DCS 59, DCS 78, DCS 107 and DCS 99). DCS 78 is the male line involved in the development of prominent hybrid DCH 215 and the newly released variety DCS 107 was derived from cross of DCH 177 and JI 133. Custer IIIc included one pistillate line VP-1, which is the first pistillate line developed in India and five male lines. Among five male lines, DCS 38 and DCS 81 are cross derivatives involving VP-1 while DCS 106 derived from a multiple cross involving four F1s and six different parents is highly diverse the cluster. Principal coordinate analysis ( $\mathrm{PCoA}$ ) was carried out on the same SSR data set. The results of PCoA showed that the first two axes captured only $10.7 \%$ and $8.3 \%$ of total variance, respectively and did not show any strong groupings (Figure 2).

\section{Population structure}

To further verify the results of the cluster and PCoA analyses, the programme structure was used. Population structure means a nonrandom distribution of the genetic diversity, which changes over time in species between groups (Hamrick and Loveless, 1989). 
The Structure uses a model based on a Bayesian clustering approach to infer the population structure (Pritchard et al., 2000). The structure analysis was performed by setting number of clusters $(\mathrm{k})$ from 1 to 10 with 10 replications for each $\mathrm{K}$. The $\mathrm{LnP}(\mathrm{D})$ showed a constant increase with the increasing subpopulation number $(\mathrm{K})$ and no significant clear cut-off was observed based on the LnP(D) (Figure 3a). However, delta-K (DK) analysis of $\operatorname{LnP(D)}$ (Evanno et al., 2005), showed a sharp peak at $K=3$, suggesting three populations within the collection of 60 genotypes (Figure $3 b$ ). Based on the threshold value of the membership coefficient $(\geq 0.75), \quad 40$ accessions were assigned to three populations (namely, P1, P2, P3 and P4) and the remaining 20 accessions to the admixture group. The bar plot showing the population structure for $\mathrm{K}=3$ also indicated e populations with clear admixture in the individuals (Figure 4). P1 comprised of $21(52.5 \%), \mathrm{P} 2$ comprised of $11(27.5)$ and P3 comprised of 8 genotypes (20\%). The average gene diversity between individuals in the same cluster was $0.445,0.427$ and 0.347 for P1, P2 and P3 respectively. The mean Fst values within $\mathrm{P} 1, \mathrm{P} 2$ and $\mathrm{P} 3$ were 0.272 , 0.270 and 0.46 . AMOVA partitioned the total genetic variance into two components: among and within populations. Maximum of genetic variation was explained by individuals within the populations $(84.79 \%)$ but not by individuals among the populations (13.21\%). STRUCTURE is one of the most widely used software for population analysis, which helps to assess the patterns of genetic structure in a subset of samples (Porras-Hurtado et al., 2013). The average distances and Fst values within the main populations were low and $33.3 \%$ of the genotypes are admixtures. The populations are not further subdivided into sub populations. The Fst values among major genotypic groups were low (Fst $<0.2)$ suggesting low genetic divergence and the genetic structuring was weak. Senthilvel et al., (2016) found that there was no marked genetic structuring within the collection of 144 inbred lines derived from a core collection of castor.

Table.1 List of castor genotypes used for genetic diversity studies

\begin{tabular}{|l|l|l|l|}
\hline S.No & Genotype & Pedigree & Morphological characters \\
\hline $\mathbf{1}$ & VP-1 & $\begin{array}{l}\text { (JP-5 } \times \text { 28006) } x \\
\text { TSP10R x JI-15) F }\end{array}$ & $\begin{array}{l}\text { Green, triple bloom, spiny, dwarf condensed nodes, } \\
\text { cup shaped leaves, pistillate line }\end{array}$ \\
\hline $\mathbf{2}$ & $48-1$ & HO x MD & Red, double bloom, non-spiny \\
\hline $\mathbf{3}$ & AKC-1 & - & Red, double bloom, spiny \\
\hline $\mathbf{4}$ & Haritha & PPL-4 X 48-1 & Green, double bloom, spiny \\
\hline $\mathbf{5}$ & SKI 215 & - & Red, double bloom, non-spiny, \\
\hline $\mathbf{6}$ & JI-220 & - & Green, spiny, triple bloom \\
\hline $\mathbf{7}$ & JI-336 & Geeta $\times$ JI -226 & Red, spiny, triple bloom \\
\hline $\mathbf{8}$ & JP-81 & SKP-4 x 48-1 & Red, spiny, double bloom \\
\hline $\mathbf{9}$ & JP-87 & JP-68 x SKI-73 & Red, spiny, Triple bloom \\
\hline $\mathbf{1 0}$ & DCS-1 & $240 \times$ Bhagya & Red, non-spiny, double bloom \\
\hline $\mathbf{1 1}$ & DCS-2 & Bhagya x CO-1 & Red, spiny, double bloom \\
\hline $\mathbf{1 2}$ & DCS-3 & Bhagya X H-86 & Red, spiny, double bloom \\
\hline $\mathbf{1 3}$ & DCS-5 & $240 \times$ Bhagya & Red, spiny, double bloom \\
\hline $\mathbf{1 4}$ & DCS-9 & $240 \times$ Bhagya & Red, spiny, double bloom \\
\hline $\mathbf{1 5}$ & DCS-16 & Selection from HC-8 & Green, spiny, double bloom \\
\hline $\mathbf{1 6}$ & DCS-18 & Bhagya X HC-8 & Red, non-spiny, triple bloom \\
\hline $\mathbf{1 7}$ & DCS-22 & T-3 x 279 & Green, spiny, triple bloom \\
\hline & & & \\
\hline
\end{tabular}




\begin{tabular}{|c|c|c|c|}
\hline 18 & DCS-25 & EC-169803 x Aruna & Red, spiny, double bloom \\
\hline 19 & DCS-33 & EC-169803 x Aruna & Green, spiny, double bloom \\
\hline 20 & DCS-37 & $163-1 \times 43-3$ & Red, spiny, double bloom \\
\hline 21 & DCS-38 & $163-1-11 \times 1501-4$ & Green, non- spiny, double bloom \\
\hline 22 & DCS-45 & $163-1 \times 99-2$ & Red, spiny, double bloom \\
\hline 23 & DCS-47 & $163-1-11 \times 1501-4$ & Red, spiny, double bloom \\
\hline 24 & DCS-49 & EC-169803 x Aruna & Green, spiny, double bloom \\
\hline 25 & DCS-50 & EC-169803 x Aruna & Red, spiny, double bloom \\
\hline 26 & DCS-51 & EC-169803 x Aruna & Red, spiny, double bloom \\
\hline 27 & DCS-53 & $163-1-11 \times 1501-4$ & Red, spiny, double bloom \\
\hline 28 & DCS-59 & EC-169803 x Aruna & Green, spiny, double bloom, Papaya leaf type \\
\hline 29 & DCS-60 & EC-169803 x Aruna & Green, spiny, zero bloom \\
\hline 30 & DCS-63 & EC-169803 x Aruna & Red, spiny, double bloom \\
\hline 31 & DCS-68 & $163-3 \times 43-3$ & Red, spiny, Triple bloom, compact leaf type \\
\hline 32 & DCS-78 & Male version of DPC-11 & Green, spiny, double bloom \\
\hline 33 & DCS-79 & LRES-17 x REC-9 & Red, spiny, double bloom \\
\hline 34 & DCS-80 & LRES-17 x REC-9 & Red, spiny, double bloom \\
\hline 35 & DCS-81 & LRES-17 x REC-9 & Red, spiny, double bloom \\
\hline 36 & DCS-84 & LRES-19 x TMV-5 & Red, spiny, double bloom \\
\hline 37 & DCS-86 & LRES-19 x 48-1 & Green, spiny, double bloom \\
\hline 38 & DCS-86-1 & LRES-19 x 48-1 & Green, spiny, triple bloom \\
\hline 39 & DCS-89 & $163-1-10-2 \times 48-1$ & Red, non-spiny, double bloom \\
\hline 40 & DCS-91 & $163-1-11 \times 1501-4$ & Green, spiny, Triple bloom \\
\hline 41 & DCS-92 & NES-19 x RMC-3 & Green, spiny, Triple bloom \\
\hline 42 & DCS-93 & NES-19 x RMC-3 & Red, spiny, double bloom \\
\hline 43 & DCS-94 & NES-19 x RMC-3 & Green, spiny, triple bloom \\
\hline 44 & DCS-96 & 87-V-2-1 x RMC-3 & Green, spiny, triple bloom \\
\hline 45 & DCS-97 & 163-1-10-2 x VI-9 & Red, spiny, double bloom \\
\hline 46 & DCS-99 & DPC 11 x DCS 33 & Green, spiny, double bloom \\
\hline 47 & DCS-100 & DPC 11 x DCS 43 & Green, spiny, double bloom \\
\hline 48 & DCS-102 & DPC 11 x DCS 43 & Green, spiny, double bloom \\
\hline 49 & DCS-103 & M 571 x REC 2 & Red, spiny, double bloom \\
\hline 50 & DCS-104 & M 584 x REC 2 & Red, spiny, double bloom \\
\hline 51 & DCS-105 & NES $19 \times$ RMC 3 & Red, spiny, triple bloom \\
\hline 52 & DCS-106 & DCH 207 x DCH 215 & Green, non-spiny, triple bloom \\
\hline 53 & DCS-107 & DCH-177 x JI-133 & Green, spiny, double bloom \\
\hline 54 & DPC-9 & $\begin{array}{l}\text { VP-1 x 128-1 (Bhagya x } \\
\text { CO-1) }\end{array}$ & Green, spiny, zero bloom pistillate line \\
\hline 55 & DPC-11 & $163-1-11 \times 1501-4$ & Green, spiny, double bloom pistillate line \\
\hline 56 & DPC-13 & VP-1 x REC-128-1 & Red, spiny, zero bloom pistillate line \\
\hline 57 & DPC-14 & VP-1 x REC-128-1 & Green, spiny, triple bloom pistillate line \\
\hline 58 & DPC-15 & NES-6 x DCS-12 & $\begin{array}{l}\text { Red, spiny, triple bloom, papaya leaf type pistillate } \\
\text { line }\end{array}$ \\
\hline 59 & DPC-16 & NES-6 $\times$ TMV-5 & Red, spiny, zero bloom, pistillate line \\
\hline 60 & DPC-17 & M 619 x JI 225 & Red, spiny, single bloom, pistillate line \\
\hline
\end{tabular}


Table.2 Number of alleles (n), major allele frequency (MAF), gene diversity (He), Polymorphic Information content (PIC) calculated for 30 polymorphic EST-SSR primers

\begin{tabular}{|c|c|c|c|c|c|c|c|}
\hline Primer & Motif & Forward primer & Reverse primer & $\mathrm{Na}$ & MAF & He & PIC \\
\hline mRCDOR07 & $(\mathrm{CT}) 23$ & CTTACGCAACAAATCAACCC & GATAGAGGAGGAGAGGTCGC & 3 & 0.63 & 0.50 & 0.42 \\
\hline mRCDOR09 & (TC) 15 & CTCCTTTCACGTCCATCATC & GAGAGTGGCATTGTAATGGG & 3 & 0.52 & 0.52 & 0.40 \\
\hline mRCDOR13 & $(\mathrm{AG}) 12$ & TCCGCTCCTAGACAAAGAAA & GACCTGTTGTAGCCCATGAC & 2 & 0.67 & 0.44 & 0.35 \\
\hline mRCDOR20 & (TA) 13 & CGCAAACCAATCTCTCTCTC & TCTGATCACCTTGCTGCATA & 3 & 0.52 & 0.58 & 0.49 \\
\hline mRCDOR22 & (TC)13 & GCCTCСТTCСТCAACATACA & GGCACCACCATTAACAAAAG & 2 & 0.52 & 0.50 & 0.37 \\
\hline mRCDOR24 & (TC)13-(TA)12 & TCTTCCTGGGCCATACACTA & AAGCCTTGGGTTTTGGTATC & 3 & 0.59 & 0.55 & 0.47 \\
\hline mRCDOR26 & (CT)12 & СTCGCCTCTCTCCTTCTCTT & TCTACCATCTCCTCGTAGCG & 3 & 0.65 & 0.47 & 0.37 \\
\hline mRCDOR28 & (TC)24 & ACAGCTCAATTTCTTGCTGC & TAACACAAAACCACTTGGGC & 2 & 0.58 & 0.48 & 0.36 \\
\hline mRCDOR49 & (CT)14 & CCCTGTCAAAACATTCTTCG & TGTTGTTGGGATGAATAGGG & 3 & 0.47 & 0.61 & $0.53^{*}$ \\
\hline mRCDOR50 & $(\mathrm{AT}) 15$ & TCGAAACTCGTCCTCTGTTC & GCAAAACAGATTCGATGCTC & 2 & 0.55 & 0.54 & 0.46 \\
\hline mRCDOR55 & (TC) 12 & TCCTCTTCCTCTTCCTCGTT & CGTCAGCCATGGTTAGAGAC & 4 & 0.43 & 0.62 & $0.55 *$ \\
\hline mRCDOR69 & $(\mathrm{AT}) 12$ & GGCAGAAAAGTTGAGATTGC & CAAACACAGTTGGAAAAGGC & 3 & 0.55 & 0.55 & $0.50 *$ \\
\hline mRCDOR76 & $(\mathrm{AG}) 14$ & AGGATCAAAAGATGCACAGC & CAATGACAATGGCGACTGAT & 3 & 0.53 & 0.59 & $0.51 *$ \\
\hline mRCDOR88 & (TC) 13 & GGCACGAGGGGATTATCTA & ACAACTGACGGGAAACTGAA & 3 & 0.64 & 0.51 & 0.44 \\
\hline mRCDOR92 & (GA)12 & GCATGTTTATACCGCTGCTT & TGGAAAGTTTCTCTTGGCTG & 3 & 0.52 & 0.56 & 0.46 \\
\hline mRCDOR103 & $(\mathrm{CAG}) 8$ & AATGACAGCGAGTTCAGGAG & GCCATAAACTCACCACAACC & 2 & 0.50 & 0.50 & 0.38 \\
\hline mRCDOR106 & $(\mathrm{CCA}) 9$ & CCAATCTGTTCGATTTCACC & GAATTGGATTACCACCACCA & 3 & 0.39 & 0.65 & $0.57 *$ \\
\hline mRCDOR113 & $(\mathrm{AAG}) 8$ & TGCCTACTTCTTAAAGGCGA & TCTCGAACATATCGTGAGCA & 3 & 0.68 & 0.46 & 0.39 \\
\hline mRCDOR119 & $(\mathrm{CAC}) 9$ & САССТСАСТТТСТСССТССТ & AACGAGTCGGTTTGATTGAG & 4 & 0.61 & 0.51 & 0.43 \\
\hline mRCDOR121 & (CTG)9 & CACCAGGACAACTCAATTCC & GGATTACGGAGACGAGGTTT & 2 & 0.58 & 0.49 & 0.37 \\
\hline mRCDOR130 & (ACA) 10 & GAAGCTACGTCTGTCCCAAA & GTGGGTATTGTAGAGGGGCT & 3 & 0.64 & 0.51 & 0.47 \\
\hline mRCDOR147 & $(\mathrm{GCT}) 9$ & GCTTAGCTTTGTGTCTCCCA & ACCAACCCTGCATAGCATTA & 3 & 0.60 & 0.54 & 0.47 \\
\hline mRCDOR153 & $(\mathrm{CAC}) 8$ & TCCCTGTTAAACCTGATTGC & CAGAAGTTGGGGTTATCGTG & 4 & 0.52 & 0.61 & $0.55^{*}$ \\
\hline mRCDOR166 & (CAC)9 & ACCCCACACGACCTTTCTAC & TGTTGCAGCTTGACACATCT & 3 & 0.43 & 0.53 & 0.47 \\
\hline mRCDOR175 & $(\mathrm{GGA}) 10$ & AAATCGGGGAAGAGAATGTC & TGTTGCTGTTGTTGTTACCG & 2 & 0.59 & 0.48 & 0.37 \\
\hline mRCDOR177 & (TTC) 11 & CACAGTACGGTCCTTCTGGT & TACAAGAACAAAACGCCACC & 3 & 0.47 & 0.62 & $0.59 *$ \\
\hline mRCDOR181 & $(\mathrm{GAG}) 8$ & TGAGAGGTTGCAAGGTAAGG & CCCGCATTAATGTTCCTATG & 3 & 0.52 & 0.39 & 0.43 \\
\hline mRCDOR203 & (AAAG)6 & ACCTCAAACAAAGCCCAAAC & ACTAAAACAAGGGTGCCTCC & 3 & 0.47 & 0.60 & $0.50 *$ \\
\hline mRCDOR206 & (AAAG)6 & CGATCGCTCCTTTTCTTTTC & ATCGGTAGCCAAACAAGTGA & 2 & 0.59 & 0.49 & 0.37 \\
\hline \multirow[t]{2}{*}{ mRCDOR240 } & (TC) 10 & CGTTAAAAGACCAGGAACCA & ATGCTATCTTGCAAAGCCAC & 3 & 0.38 & 0.56 & $0.62 *$ \\
\hline & & & Average & 2.83 & 0.54 & 0.53 & 0.45 \\
\hline
\end{tabular}

*Indicates PIC values $>0.5$. 
Fig.1 Neighbour joining tree showing relationship of 60 genotypes of castor

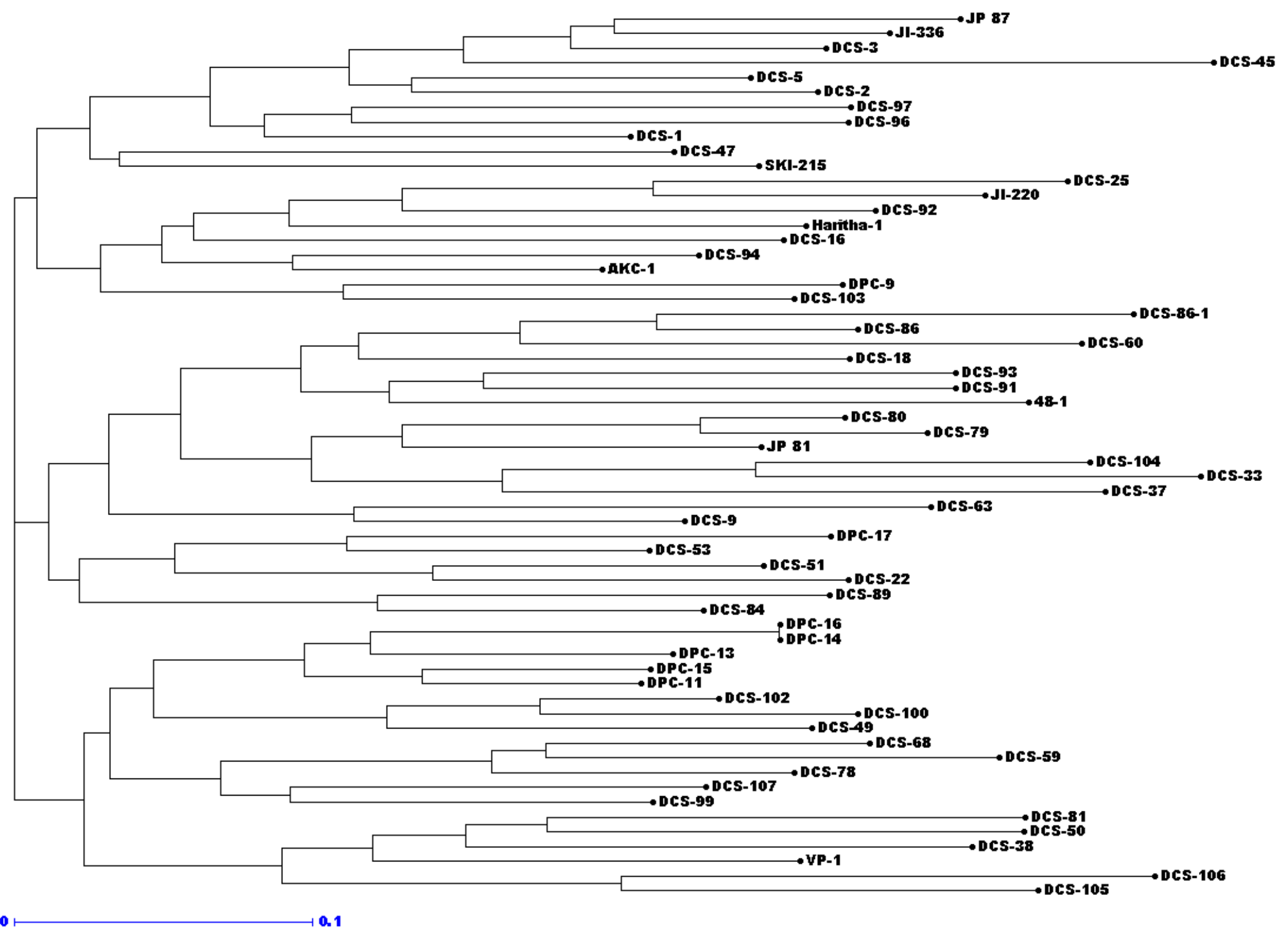


Fig.2 Principal coordinate analysis (PCoA) of 60 genotypes of castor. Axes- $1(10.7 \%)$ and Axes-2 (8.3\%) did not separate the genotypes into major groups

\section{Factorial analysis: (Axes 1/2)}

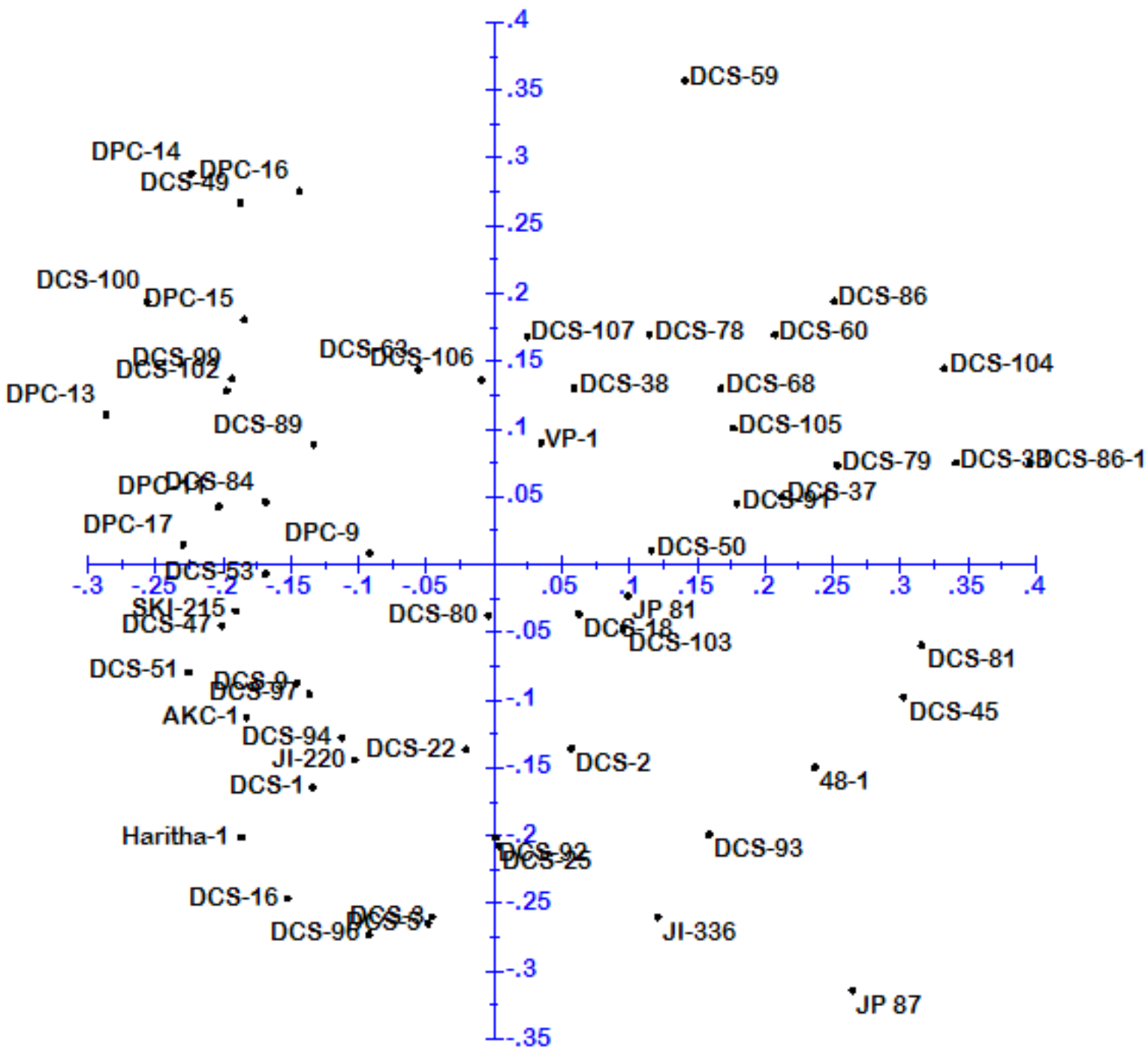


Fig.3 Determination of the optimal value of $\mathrm{K}$ for the genotypes.

(a) Log probability of data, $\mathrm{L}(\mathrm{K})$ averaged over the replicates (b) Plot of Delta K calculated as the mean of the second-order rate of change in likelihood of $\mathrm{K}$ divided by the standard deviation of the likelihood of $\mathrm{K}$ as per Evannoet al. (2005)

(a)

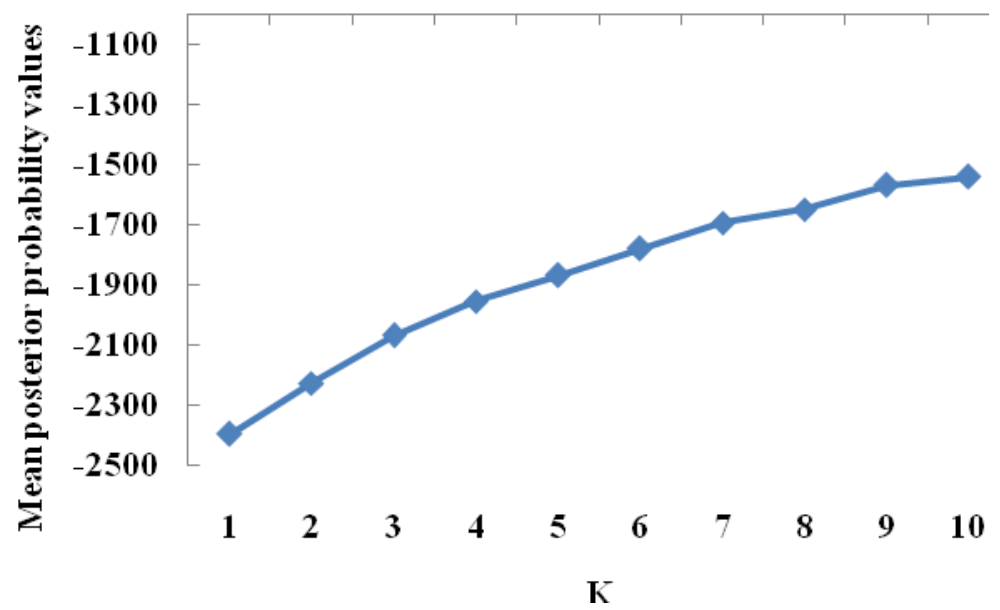

(b)

Delta $\mathrm{K}=$ mean $(|\mathrm{L} "(\mathrm{k})| \mathrm{SD}(\mathrm{L}(\mathrm{k}))$

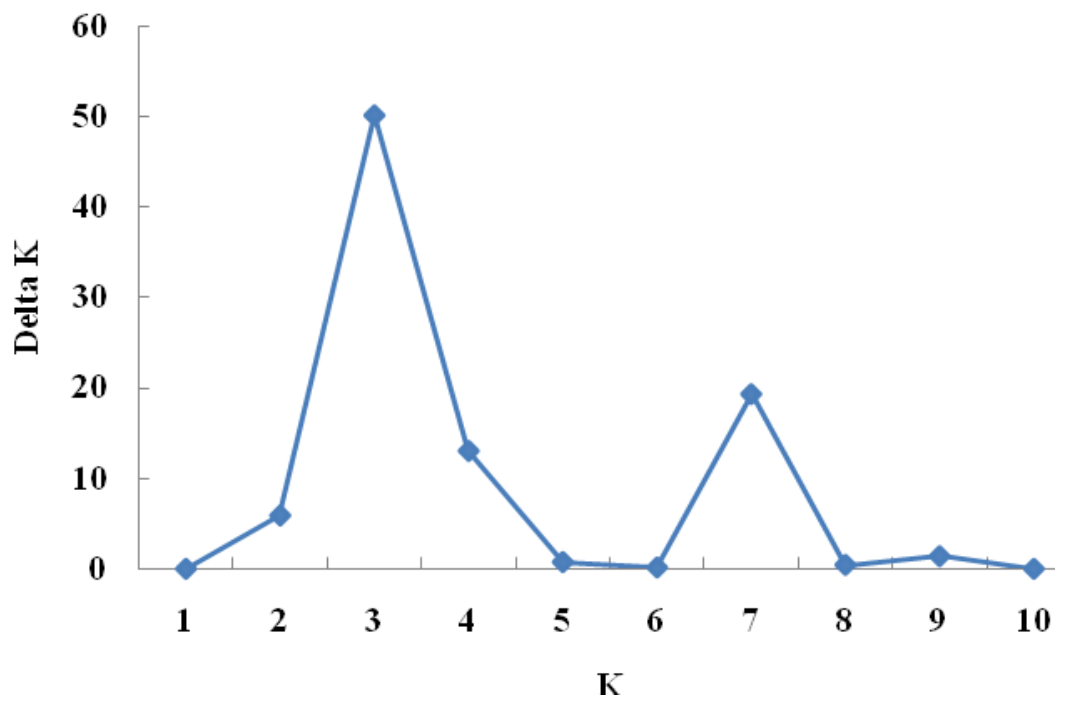


Fig.4 Model based clustering of castor genotypes into three populations (P1, P2 and P3)

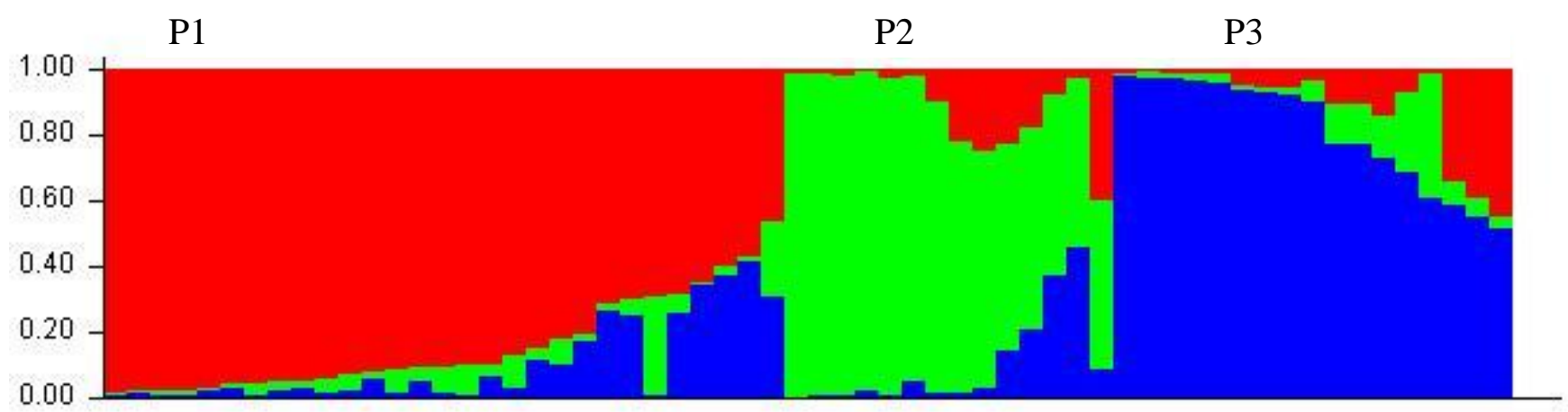

Both the NJ tree and STRUCTURE grouped the genotypes into 3 major clusters that were almost comparable. The most divergent population P3 detected by STRUCTURE consisted of 14 accessions, which were also present in cluster III. A large number of the genotypes $(33.3 \%)$ were classified under admixture group suggesting that they have mixed ancestry because of the common parental lines. The results of NJ clustering, PCoA and model based STRUCTURE analyses clearly suggested that there was low allelic diversity and weak genetic structure in the castor genotypes used in the breeding programme of castor. As the castor is highly cross pollinated, low level of population differentiation is expected due to extensive gene flow among individuals.

In conclusion, castor is being cultivated predominantly in India. It is good to go through the breeding programs and selection history to understand the extent of variability existing in the on-going breeding populations. Most of the earlier studies, assessment of the extent of genetic diversity of castor was reported in naturally occurring populations (Wang et al., 2013; Kanti et al., 2014, 2015), land races (Seo et al., 2011); inbreds from core correction (Senthilvel et al., 2016) and germplasm maintained in gene banks (Allan et al., 2008; Foster et al., 2010; PecinaQuintero et al., 2013). In the present study, a set of 60 elite parental lines commonly used in the castor crossing programme have been molecularly characterized for broadening the genetic base of castor. The molecular data indicated the low SSR allelic diversity with weak or low population structure. Hence, the breeding lines have to be diversified using mutations, crossing diverse lines from different regions or geographically isolated lines for harnessing heterosis, and to develop better hybrids.

\section{Acknowledgements}

The authors are thankful to Director, ICARIndian Institute of Oilseeds Research (ICARIIOR) for extending all the facilities for the research work.

\section{References}

Allan, G., Williams, A., Rabinowicz, P.D., Chan, A.P., Ravel, J. and Keim, P. 2008. Worldwide genotyping of castor bean germplasm (Ricinus communis L.) using AFLP and SSRs. Genet Resour Crop Evol., 55: 365-378.

Anjani, K. 2012. Castor genetic resources: a primary gene pool for exploitation. Ind Crops Prod., 35: 1-4.

Athma, P., Vaidynath, K. and Reddy, T.P. 1982. Peroxidase isoenzyme studies in certain varieties of Ricinus communis $\mathrm{L}$. Indian J Bot., 5: 178-182. 
Bajay, M.M., Pinheiro, J.D., Batista, C.E.A., Nobrega, M.B.M. and Zucchi, M.I. 2009. Development and characterization of microsatellite markers for castor (Ricinus communis L.), an important oleaginous species for biodiesel production. Conserv genet resour., 237-239.

Costa, M.N, Pereira, W.E., Bruno, R.L.A., Freire, E.C., Noberega, M.B.M., Milani, M. and Oliveira, A.P. 2006. Genetic divergence between castor bean accessions and cultivars through multivariate statistics. Pesq Agropec Bras., 41: 1617:1622.

Doyle, J.J. and Doyle, J.L.1990. Isolation of plant DNA from fresh tissue. Focus, 12: 13-15.

Durga Rani, Ch.V., Vishnuvardhan Reddy, A. and Anuja, G. 2010. Genetic divergence in castor (Ricinus communis L.). J Oilseeds Res., 27: 126-128.

Earl, D.A. and VonHoldt, B.M.2012. Structure harvester: a website and program for visualizing structure output and implementing the Evanno method. Conserv Genet Resour., 4: 359-361.

Eujayl, I., Sorrells, M.E., Baum, M., Wolters, P and Powell, W. 2002. Isolation of ESTderived microsatellite markers for genotyping the $\mathrm{A}$ and $\mathrm{B}$ genomes of wheat. Theor Appl Genet., 104: 339-407.

Evanno, G., Regnaut, S. and Goudet J. 2005. Detecting the number of clusters of individuals using the software Structure: a simulation study. Molecular Ecol., 14: 2611-2620.

FAOSTAT.2013. Food and Agriculture Organisation of the United Nations

Figueiredo, N.A., Almeida, F.A.C., Gouveia, J.D.E., Nobrega, M.B.M., Carneiro, R.M., Pedroza, J.P. 2004. Genetic divergence in accessions of castor bean (Ricinus communis L.) based on characteristics of seed. J Biol Earth Sci., 4:1-10.

Foster, J.F., Allan, G.J., Chan, A.P., Pablo, D., Rabinowicz, Jacques Rave., Paul, J., Jackson, Paul Keim. 2010. Single nucleotide polymorphisms for assessing genetic diversity in castor bean (Ricinus communis), BMC Plant Biol., 10: 13.

Gajera, B.B, Kumar, N., Singh, A.S., Punvar, B.S., Ravikiran, R., Subhash, N. and Jadeja, G.C. 2010. Assessment of genetic diversity in castor (Ricinus communis L.) using RAPD and ISSR markers. Ind Crops Prod., 32(3): 491-498.

Golakia, P.R., Madaria, R.B., Kavani, R.H and Mehta, D.R. 2004. Gene effects, heterosis and inbreeding depression in castor, Ricinus communis L. J Oilseeds Res., 21: 270-273.

Hamrick, J and Loveless, M. 1989. The genetic structure of tropical tree populations: associations with reproductive biology. Evol Ecol Plant, 33: 129-146.

Jeong, G.T. and Park, D.H.2009. Optimization of bio-diesel production form castor oil using response surface methodology. Appl Biochem Biotech., 156:431-441.

Kanti, M., Anjani, K., UshaKiran, B. and Vivekananda. 2015. Agro-morphological and molecular diversity in castor (Ricinus communis L.) germplasm collected from Andaman and Nicobar Islands, India. Czech J Genet Plant Breed., 51: 96-109.

Kanti, M., Anjani, K. and Venkatramya. 2014. Molecular diversity in castor germplasm collection originated from North-Eastern province of India. Int J Res Sci Inn., $1: 1: 6$.

Kulkarni, L.G. and Ramanamurthy, G.V. 1977. Castor. ICAR, New Delhi.

Kupper, C.P.J.M., Chitatto, A., Zucchi, M., Colombo, C., Carbonell, S., Cosata, M.J.M., Gazaffi, R., Franco, G.A.A., Decampos, T. and De souza, A.2011. Genetic diversity in cultivated carioca common bean based on molecular marker analysis. Genet Mol Biol., 34: 88.

Lavanya, C. 2002. Sensitivity and variations of sex expression in response to environmental changes in castor. Indian $J$ Genet Pl Br., 6: 232-237.

Lavanya, C., Chakrabarthy, S.K, Ramachandran, M., Rao, C.H. and Raoof, M.A. 2003a. Development of wilt resistant pisitillate lines in castor through mutation breeding. J Oilseeds Res., 20: 
$48-50$.

Lavanya, C. and Chandramohan, Y. 2003b. Combining ability and heterosis for seed yield and yield components in castor. $J$ Oilseeds Res., 20: 220-224.

Lavanya, C. and Gopinath, V. 2008. Study on inheritance of morphological characters and sex expression in pistillate lines of castor. Indian J Genet Pl Br., 68: 275282.

Lavanya, C., Murthy, G.S.S. and Lakshminarayana, M. 2008. Use of gamma rays for the development of leaf hopper resistant pistillate lines in castor (Ricinus communis L.). In: Proceeding of International Symposium on Induced Mutations in Plants, IAEA, Vienna, Austria. Int. Atomic Energy Agency, Vienna.

Lavanya, C., Ramanarao, P.V. and Gopinath, V.V.2006. Studies on combining ability and heterosis in castor hybrids. $J$. Oilseeds Res., 23: 174-177.

Lavanya, C. and Solanki, S.S. 2010. Crop improvement of castor: The challenges ahead. In Hegde DM. (Ed). Research and development in castor: present status and future strategies. Indian Society of Oilseeds Research, Hyderabad 36-55.

Liu, K. and Muse, S.V. 2005. Power Marker: an integrated analysis environment for genetic marker analysis. Bioinformatics, 21: 2128-2129.

Maestri, E., Malcevschi, A., Massari, A. and Marmiroli, N. 2002. Genome analysis of cultivated barley (Hordeum vulgare) using sequence tagged molecular markers, Estimates based on divergence based on RFLP and PCR markers derived from stress-responsive genes, and simple sequence repeats (SSRs). Mol Genet Genomics, 267: 186-201.

Milani, M., Dantas, F.V. and Martins, W.F.S. 2009. Genetic divergence among castor bean genotypes by morphological and molecular characters. Rav Bras Oleag Fibro, 13:61-71.

Moshkin, V.A. 1986. Economic importance and regions of cultivation of castor, In:
MoshkinV A (ed.) Castor. Moscow:

Kolos 1-5.

Pecina-Quintero, P.V., Anaya-Lopez, J.L., Nunez-Colin, C.A., ZamarripaColmenero, A., Montes-Garcia, N., SolisBonilla, J.L. and Aguilar-Rangel, M.R. 2013. Assessing the genetic diversity of castor bean from Chiapas, México using SSR and AFLP markers. Ind. Crops Prod., 41: 134-143.

Perrier, X. and Jacquemoud-Collet, J.P. 2006. DARwin software http://darwin.cirad. fr/.

Porra Hurtado, L., Ruiz, Y., Santos, C., Phillips, C., Carracedo, A. and Lareu, M.V. 2013. An overview of STRUCTURE: applications, parameter settings, and supporting software: Front Genet., 4:98.

Pritchard, J.K., Stephens, M. and Donnelly, P. 2000. Inference of population structure using multilocus genotype data. Genet., 155: 945-959.

Qiu, L., Yang, C., Tian, B., Yang, J.B. and Liu, A. 2010. Exploiting EST databases for the development and characterization of ESTSSR markers in castor bean (Ricinus communis L.). BMC Plant Biol., 10: 1-10.

Ramana, P.V., Lavanya, C. and Ratnasree, P. 2005. Combining ability and heterosis studies under rainfed conditions in castor (Ricinus communis L.). Indian J. Genet. Plant Breed., 65: 325-326.

Remington, D.L., Thornsberry, J.M., Matsuola, Y., Wilson, L.M., Whitt, S.R., Doebley, J., Kresovich, S., Goodman, M.M. and Buckler, E.S. 2001. Structure of linkage disequilibrium and phenotypic associations in the maize genome. Proc Natl Acad Sci., USA 98: 11479-11484.

Rivarola, M., Foster, J.T., Chan, A.P., Williams, A.L., Rice, D.W., Liu, X., MelakeBerhan, A., Huot Creasy, H., Puiu, D., Rosovitz, M.J., Khouri, H.M., Beckstrom-Sternberg, S.M., Allan, G.J, Keim, P., Ravel, J. and Rabinowicz, P.D. 2011. Castor bean organelle genome sequencing and worldwide genetic diversity analysis. PLoS ONE, 6: 1-9.

Sathaiah, V. and Reddy, T.P. 1984. Qualitative and Quantitative ananlysis of peroxidase 
and esterase enzymes in (Ricinus communis L.). India J Bot., 7: 68-73.

Senthivel, S., Mobeen Shaik., Anjani, K., Ranjan, K.Shaw., Sarada, S., Usha Kiran, B. 2016. Genetic variability and population structure in a collection of inbred lines derived from a core germplasm of castor. $J$ Plant Biochem Biotech., DOI: 10.1007/s13562-0160356-8.

Seo, K.I., Lee, G.A., Ma, K.H., Hyun, D.Y, Park, Y.J, Jung, J.W., Lee, S.Y, Gwag, J.G, Kim, C.K. and Lee, M.C. 2011. Isolation and characterization of 28 polymorphic SSR loci from castor bean (Ricinus communis L.). J Crop Sci Biotechnol., 14: 97-103.

Sevagaperumal, S., Rangaswamy, P., Muppidathi, N. 2000. Genetics divergence studies in castor. Madras Agril J., 87: 241-243.

Severino, L.S, Auld, D.L., Baldanzi, M., Candido, M.J.D., Chen, G., Crosby, W., Tan, D., He, X., Lakshmamma, P., Lavanya, C., Machado, O.L.T., Mielke, T., Milani, M., Miller, T.D., Morris, J.B., Morse, S.A., Navas, A.A., Soares, D.J., Sofiatti, V., Wang, M.L., Zanotto, M.D. and Zieler, H. 2012. A review on the challenges for increased production of castor. Agron J., 104: 853-880.

Soltis, P.S., Soltis, D.E., Tucker, T.L. and Lang, A. 1992. Allozyme variability is absent in the narrow endemic Bensoniella oregona (saifragacear). Conserv Biol., 131-134.

Sujatha, M., Reddy, T.P and Mahasi, M.J. 2008.
Role of biotechnological interventions in the improvement of castor (Ricinus communis L.) and Jatropha curcas L. Biotechnol Advances, 26: 424-435.

Suresh, G. 2009. Value addition and diversified uses of castor, Edited by Hegde, D.M. DOR Publications, Directorate of Oilseeds Research, Hyderabad.

Tegelstrom, H. 1992. Detection of mitochondrial DNA fragments. In: Hoelzel R (ed) Molecular genetic analysis of populations: A Practical approach. IRL Press, Oxford, UK 89114.

Thiel, T., Michalek, W., Varshney, R.K. and Graner, A. 2003. Exploiting EST database for the development and characterization of gene derived SSR-markers in barley (Hordeum vulgare L.). Theor Appl Genet., 106: 411-422.

Vivodik, M., Balazova, Z. and Galova. 2014. RAPD analysis of genetic diversity of castor bean. Int J Biol Vet Agril Food Eng., 8:615-618.

Wang, C., Li, G.R., Zhang, Z.Y., Peng, M., Yu, S.I., Luo, R. and Chen, Y.S. 2013. Genetic diversity of castor bean (Ricinus communis L.) in Northeast China revealed by ISSR markers. Biochem Syst Ecol., 51: 301-307.

Wang, H.Y., Wei, Y.M., Yan, Y.H. and Zheng, Y.L. 2007. EST-SSR DNA polymorphism in durum wheat (Triticum durum L.) collections. Genet., 48: 35-42.

Weiss, E.A. 2000. Oilseed Crops. Blackwell Science Ltd. Oxford, London. Pp. 13-15.

\section{How to cite this article:}

Usha Kiran Betha and Lavanya, C. 2019. Molecular Diversity and Population Structure in Breeding Lines of Castor (Ricinus communis L.). Int.J.Curr.Microbiol.App.Sci. 8(02): 20242038. doi: https://doi.org/10.20546/ijcmas.2019.802.236 